\title{
Ütopik Söylem Aracı Olarak Batı Sanatında Bahçe, Ada ve Yabanil Doğa Imgeleri
}

\author{
Murat Ateşli \\ Dumlupınar Üniversitesi \\ E-mail: matesli@hotmail.com
}

\begin{abstract}
$\ddot{O}_{z e t}$
Doğu uygarlıklarında olduğu gibi Batı uygarlıklarında da ütopik söylemler mutluluk vaadine bağll olarak cennet ve ideal toplum tasvirlerini kapsar. Cennet ve ütopik kavramlar, çoğu inanç ve düşünce sistemine göre insanın ölümden sonra yaşayacağına inanılan yitik bir kökenin özlemini de içeren mutluluk vaadidir. Antik dönemden bugüne bu kavramlar, çok tanrll ve tek tanrıl dinlerin söylence ve kutsal metinlerinde çoğu zaman simgesel anlatımlar biçiminde bahsedilmektedir. Sümerlerin Dilmun adını verdikleri dünyevi mutluluk diyarından başlayarak tarihsel süreç içinde ütopik söylem aracı olarak; bahçe, ada ve yabanıl doğa gibi tasvir ve anlatımlar, Antik Yunan düşünürlerden Euhemerus'un Kutsal Söylenceler'inde vurgulanan Panchaea adasinda, Platon'un Timaios ve Kritias adll diyaloglarında anlatılan Atlantis efsanesinde ve ütopik düşüncelerin çıklş kaynă̆ı olan Thomas More'un Utopia'sında olduğu gibi belirtilmiştir. Aynı şekilde, Eski Ahit'ten başlayarak semavi dinlerin kutsal kitaplarında bahsedilen cennet ve cehennem kavramlarına, insanoğlunun yitirmiş olduğu cennet özlemine attfta bulunan John Milton'un Kayıp Cennet ve Yeniden Kazanılan Cennet'inde ütopik mekânsal betimlemeler vurgulanmıştır.
\end{abstract}

Antik Greko-Romen mirasla biç̧imlendirilmiş ve Hıristiyanlık doktriniyle geliştirilmiş Batı kültürünün Yeryüzü Cenneti olgusu, yazın alanında önemli bir yer teşkil etmiş; plastik ve görsel sanatlar alanında da simgesel ve mekânsal bağlamda siklkkla kullanılmıştır. Batı sanatında manzara resim geleneğine bağll olarak bahçe, ada ve yabanıl doğa imgelerinin ilk örnekleri: Bronz Çağı uygarlıklarından Minos uygarlığının Thera adasında bulunan Bahar Manzarası adlı duvar resmiyle birlikte, Pompei'deki şehir kalıntılarının büyük bir kısmında ve Roma yakınlarında yer alan Prima Porta'daki Livia Villası'nda fresk ve mozaiklerde görülür. Rönesans'tan bugüne, gerek ikonolojik ve mitolojik bağlamda olsun; gerekse ütopik bir düşüncenin yansıması biçiminde olsun bu gelenek farkl materyal ve yaklaşımlarla devam etmiş̧tir. 19. yüzylldan itibaren ütopik söylemler siyasi ve toplumsal anlamlar bağlamında değerlendirilmiştir. Özellikle 20. yüzyılda, ütopik söylem avangart sanatçıların arasında sanatsal pratiklerinin nihai amacı olarak vurgulanmış; ayrıca, bu ülküsel yaklaşımlar etrafinda toplumsal ve siyasi söylemler üretilmiştir. Bu çalışmanın amacı; Batı sanatında tarihsel süreç açısından, bahçe, ada ve yabanıl doğa görünümleri üzerinden ütopya kavramının nasıl betimlenip ve yorumlandı $\breve{g l d}$ ır.

Anahtar Kelimeler: Ada, bahçe,Batı sanatı, ütopya, yabanıl doğa imgeleri. 


\title{
As a Means of Utopian Discourse; Garden, Island and Wild Nature Images in Western Art
}

\begin{abstract}
The utopian discourses in Western civilizations, as in Eastern civilizations, cover the depictions of paradise and an ideal society based on the promise of happiness. According to many belief and thought systems, paradise and utopian concepts are the promise of happiness that believed to live after the death of human including the longing of a lost origin. From antiquity to present these concepts are often mentioned in myths and sacred texts of the polytheistic and monotheistic religions in the form of symbolic expressions. In the historical process, starting from realm of the earthly happiness Dilmun that called by the Sumerians, as a means of utopian discourse; garden, island, and like a wild nature, description and narrations have been indicated as in Panchaea Island that described in the Euhemerus's Sacred History, as with the legend of Atlantis that stated in the Plato's Timaeus and Critias dialogues from Ancient Greek philosophers, and in Thomas More's Utopia which is the output source of utopian thinking. Likewise, starting from the Old Testament; utopian spatial depictions have been highlighted in the Milton's Paradise Lost and Paradise Regained that are made references to longing to have lost paradise of mankind that are mentioned the concepts of heaven and hell in the scriptures of the Abrahamic religions.

Earthly Paradise phenomenon of Western culture that enhanced by Christianity doctrine, and formatted with Ancient Greco-Roman heritage, has had an important place in the literature; been used frequently in the symbolic and spatial context in the plastic and visual arts as well. In Western art, as a based on the landscape painting tradition; the first samples of garden, island, and wild nature images are seen on the frescoes and mosaics, together with a found mural as a title known Spring Landscape, on the island of Thera of the Minoan civilization from the Bronze Age civilizations, and in a large section of ruins of the city in Pompeii, and in the Villa of Livia at Prima Porta near the city of Rome. Not only iconological and mythological context, but also in the form of the reflections of a utopian idea; this tradition has continued with different materials and approaches since the Renaissance. The utopian discourses have been evaluated in the context of political and social meanings since 19th century. Especially in the 20th century, utopian discourse is emphasized among avant-garde artists as the ultimate purpose of artistic practices; in addition, this ideal approaches have been produced social and political rhetoric around. The aim of this study is how the utopian concept has been described and interpreted by means of garden, island, and wild nature views in terms of the historical process in Western art.
\end{abstract}

Keywords: Garden, island, utopia, Western art, wild nature images.

Bu araştırmada elde edilen bulgular 12-14 Kasım 2015 tarihleri arasından düzenlenen "Felsefe, Eğitim ve Bilim Tarihi” adlı sempozyumda sözlü bildiri olarak sunulmuștur. 


\section{Giriş}

Ütopyacı yaklaşımların kökeni olan, bilinçaltı düzeyinde de insanlığın daima özlemini duyduğu ve aynı zamanda dünyevi mekânsal bağlamda daima arayış içinde hissettiği Cennet kavramı; Doğu uygarlıklarında ve diğer topluluklarda olduğu gibi Batı uygarlıklarının kutsal metinlerinde ve yazın alanında da sıkça tekrarlanan bir sözcüktür; ki bu olgu mekânsal anlamda bahçe, ada ve yabanll doğa ile özdeşleştirilir ve ütopik söylemlerin merkezinde yer alır. Örneğin, İslam inancının kutsal kitabı Kuran'ın 56. suresi olan Vakı'nın ilgili ayetlerinde vaha özlemi ile yanan ve Allah'ın lütfuna ermiş çöl evlatları için sonsuz haz ve nimetlerle dolu bahçelerin olduğundan bahsedilir. Eski Ahit'te ise (I. Musa, 2,8-10), cennetten şu şekilde bahsedilir: Tanrı sabaha doğru yarattığ 1 cennet bahçesinin içine ilk insanı koyar ve onun için topraktan göze güzel görünen ve yemesi hoş türlü türlü ağaçları yeşertti, hayat ăgacını ve iyi ile kötüyü idrak ăgacını bahçenin tam ortasına koydu. [...] bahçeyi sulamak için bir nehir aktı ve sonradan dört ana kola ayrıldı (Mayer-Tasch, 2003, 1113). Aynı şekilde John Milton'un kaleme aldığı, Batı edebiyatının cennet ve onun özlemine dair en önemli yapıtlarından birisi olan Kaylp Cennet ve Yeniden Kazanılan Cennet'te (Görüntü 1) insanlığın sahip olduğu sonsuz mutluluk bahçesini ve masumiyetini nasıl kaybettiği, tekrar insanlığın ona nasıl kavuşacağı epik bir kurgu içinde anlatılır. Kutsal metinlerde sıkça tarif edilen cennet kavramı ve miti (Görüntü 2) "insanın yazgısı ve onun Tanrıyla olan ilişkileriyle ilgili söylemlerin temelini oluşturur. Mutlak bir köken ve bir kırılma noktası olan cennet olgusu, dinsel imgelemin ötesinde, yapısal bir düzeni, tarihin, tarihsel dil ve değişikliklerin işleyişini temsil etmektedir (Doueihi, 2011, 15)”.

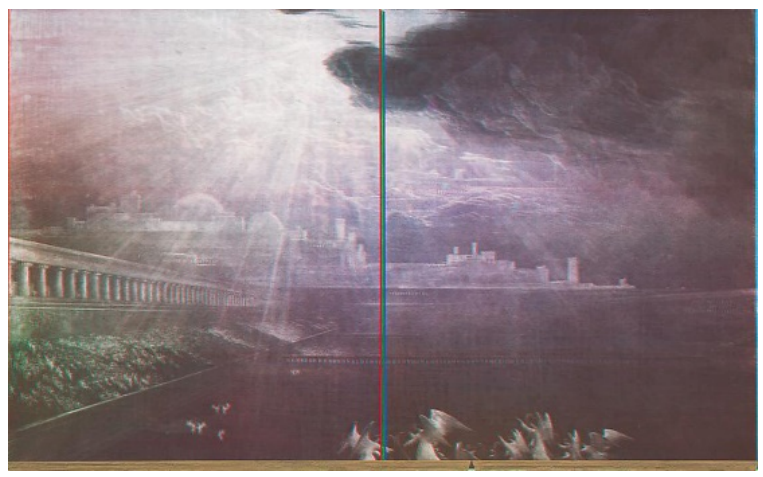

Görüntü 1. R. H. Quaytman, “Sürgün, Bölümler 20”, 82,2 x 133 cm, Ahşap üzerine yağlıboya, serigrafi ve gesso, 2010, Miguel Abreu Galerisi, New York.

Kaynak: http://www.miguelabreugallery.com ve Schwabsky, 2011, 253.

\section{Ütopik Söylemlerin Tarihsel ve Etimolojik Kökenleri}

Ütopik söylemlerle iç içe girmiş olan "çok eskilerden beri geçmişe, şimdiye ve geleceğe ilişkin cennet miti, neredeyse ulaşılmaz uzaklıklara gitmiş ve muhteşem biçimde donatılmış bir bahçe ile ilintilidir (Mayer-Tasch, 2003, 11)". Ütopik söylemlerin mekânsal kurguları; sıklıkla ideal bir uygarlığın / sitenin, toplumun diğer olumsuz ve kötüleşmiş diyarlarından -var olan ve yaşanılan dünyadan- yüksek duvarlarla yalıtılmış bahçeler ve ideal kent görünümleri şeklinde tasvir edilir veya ulaşılması zor, uçsuz bucaksız denizlerin herhangi bir yerinde bulunan bir ada, yüce dağların ardındaki gizli geçitlerin sonunda yer alan egzotik yabanıl ormanlar olarak hayal edilir. Aynı zamanda, bu cennetimsi mutluluk diyarları refah, zenginlik ve bereketin herkes tarafından adil bir biçimde paylaşıldığı mekânlar olarak düşünülür. 


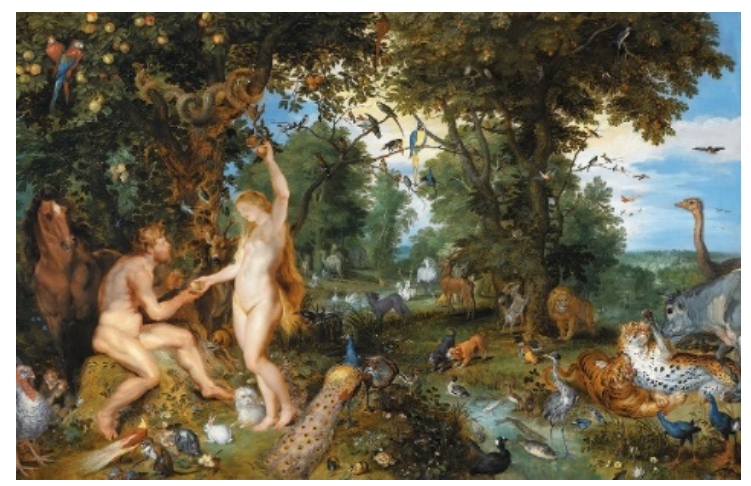

Görüntü 2. Jan Brueghel the Elder ve Peter Paul Rubens, "İnsanın Düşüşü, Adem ile Havva Aden Bahçesinde”, 74,3 x114,7 cm, Tuval üzerine yağlıboya, 1615, Maurithuis Kraliyet Resim Galerisi.

Kaynak: www.mauritshuis.nl

Batı kültürü içinde, özellikle Fransızca, Almanca ve İngilizce dillerinde Cennet kavramı iki farklı sözcükle ifade edilmiş olup, "Fransızcada ciel ve paradis, Almancada himmel ve paradies, İngilizcede ise heaven ve paradise". olarak tanımlanır. İlk sözcükler o dillerin tarihsel ve etimoljik kökenlerinden dolayı birbirlerinden ses ve yapı bakımından farklılık gösterir; buna karşın ikinci sözcüklerde ses ve yapı özelliklerinde benzerlikler görülür. Ciel, himmel ve heaven sözcükleri ilk anlamları bakımından gökyüzüyle ilişkin olarak uhrevi cenneti ifade ederken; Paradis, paradies ve paradise sözcükleri ise yeryüzü ve dünyevi bağlamda cenneti tanımlamaktadır. $\mathrm{Bu}$ bakımdan paradise olarak Cennet sözcüğünün kökeni Eski Farsça pairi-dae'-za ve Sankritçe paradésah sözcüklerinden Eski Yunancaya paradeisos'a dönüşmüş ve esas kökeni bakımından Babilcedeki pardisu ve İbranicedeki pardes sözcüklerinde vurgulanan çitle ve surla çevirmek anlamında bahçe olarak aktarılmıştır (Albig, 2009, 82; Chevalier ve Gheerbrant, 1996; Mayer-Tasch, 2003, 12). Aynı şekilde cennet sözcügü Türkçeye Arapça kökenden gelen canna sözcügünden türetilmiş olup; kutsal metinlerde bahsedilen bahçe anlamındadır. Aramca ganna / gannta sözcüğüyle aynı şekilde Akadça gananu sözcüğünün anlamı ise, korumak, etrafını çevirmek anlamına gelmektedir (Nişanyan, 2009, 91). Garden olarak bahçe kavramı da tıpk1 Aramca ve Akadçada olduğu gibi "örgü, çit, engel anlamına gelen Hint-Avrupa sözcük kökü ghordo$s$ 'tan hem Yunancadaki chortos hemde Latincedeki hortus türetilmiştir [Görüntü 3 ve 4] (Mayer-Tasch, 2003, 12)". Türkçede Bahçe'nin (Görüntü 5) etimolojik kökeni ise Farsçadan, anlamı her çeşit bahçe, kısmet, pay, mülk olan bağça sözcüğünden türetilmiştir (Nişanyan, 2009, 50-51).

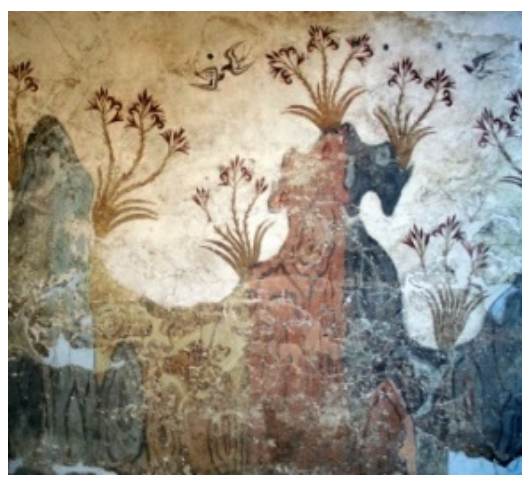

Bkz.http://www.etymonline.com/index.php?allowed_in_frame $=0 \& \operatorname{search}=$ garden $\% 2 \mathrm{C}+$ paradise $\% 2 \mathrm{C}+$ heaven $\% 2 \mathrm{C}+$ himmel\%2C + ciel\&searchmode=none ( Erişim Tarihi: 03.02.2015) 
Görüntü 3. Detay, Manzarası", Minos Akrotiri

Rekonstrüksiyon 1630-1500,

Thera. Kaynak: 142.

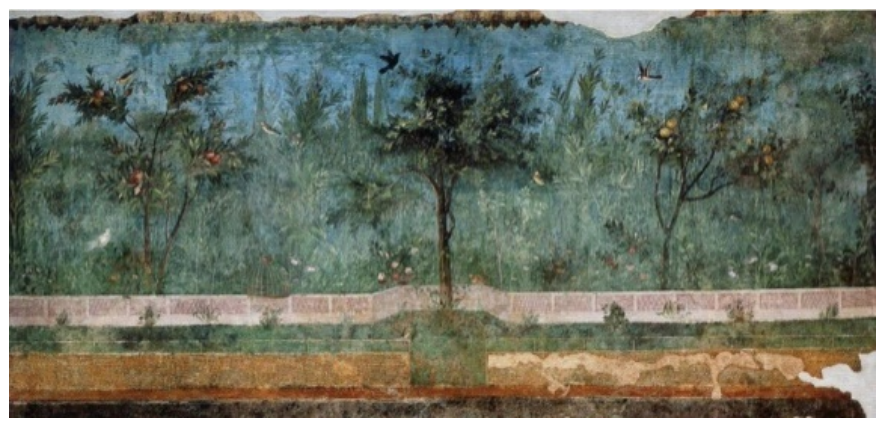

"Bahar

Uygarlığ1

Bölgesinden

Fresk, M.Ö.

Cyclades,

Stokstad, 1999
Görüntï 4. Detay, "Bahçe İkinci Stil Fresk, M.Ö. 1. Yüzyıl, Stokstad, 1999, 251.

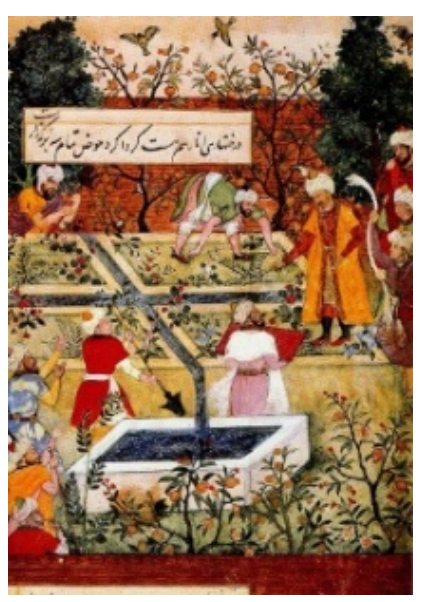

Görünümü’, Livia Villası'nda Prima Porta, Roma. Kaynak:

Görüntü 5. "Babür Şah Bahçe Çalışmalarını Denetliyor”, 16. Yüzyıl Hint Minyatürü. Kaynak: Sarkowicz, 2003, 65.

Bu kavramların sözcük kökenlerinin Hindistan'dan Antik Mısır'a kadar yayılan coğrafyadaki uygarlıklara dayanması rastlantı değildir. Nitekim insanlığın uygarlık geçmişinde bu coğrafyalarda kurulan ilk kentlerin ve devletlerin kültürel miraslarının sonucudur. Mutluluk özleminin bir duygu ve insan psikolojisiyle yakından ilişkili olmasının yanı sıra, bir mekân-yerle ilintili olduğu düşüncesi ilk defa MÖ. 4000-2000 yılları arasında, Dicle ile Fırat nehirleri arasındaki topraklarda filizlenmiştir. Ütopik kavramların etimolojik kaynakları açısından ve ütopik söylemlerin ilk örnekleri bakımından da bu coğrafyadaki uygarlıklardan Sümer ve Eski Fars kültürü önemli bir yer teşkil eder.

Sümerler, Dilmun adını verdikleri bir diyara methiyeler yazmışlardır. Kil tabletlerde Dilmun'un ne kadar temiz, ne denli nurlu bir yer olduğu anlatılmış; sözünü ettikleri bu diyarda kaynaklardan tertemiz suların fışkırdığı, toprakların her daim yemyeşil, insanlar ve hayvanların uyum içinde yaşadığı tasvir edilmiştir. (Albig, 2009, 78) 
Yazın alanında kayıtlı ilk örnekler İlkçağ'dan itibaren ütopyacı söylenceler kapsamında fantastik efsanevi bir kurgu içinde tasvir edilmiş, daha sonraki dönemlerde felsefi, dini ve siyasi içeriklere sahip metinlere dönüşmüştür. Hesiodos'un İşler ve Günler'inde bahsettiği Altın Çăg (Görüntü 6) insanın evrensel mutluluk içinde, refah, barış ve ölümsüzlükle yaşamını sürdürdüğü bir dönemdir. Platon’un Timaios ve Kritias diyaloglarında Eski Mısırlı rahiplerin Solon'a anlattıkları efsanevi Atlantis, bahçeleri, ormanları ve zenginlikleriyle tanrısal mutluluk ülkesidir. Bununla beraber, Euhemerus'un Kutsal Söylenceler'indeki Panchaea adasında tanrısal özü bozulmamış, dış dünyadan yalıtılmış biçimde yaşayan bir insan ırkının mutluluk dolu hayatları anlatılır (Görüntü 7). $\mathrm{Bu}$ söylenceler ütopyacı yazının ilk örnekleri olarak değerlendirilebilir. Erken dönem söylencelerdeki Arcadia (Görüntü 8), Atlantis (Görüntü 9), Bahtlllar Adası gibi ölümsüz ve tanrısal mutluluk adaları söylemi, Ortaçağ Hıristiyanlık doktrininde Yeryüzü Cenneti ülküsüne dönüşür, böylelikle Tanrının şefaatine ermiş inançlıların Fortunatae İnsulae adlı bu cennetimsi düşsel adada inanılır (Göktürk, 1982, Ahit'te bahsedilen Aden Bahçesi (Görüntü boyunca mitsel ve olarak Batı kültüründe edinmiş, bir ütopik Hıristiyanların dini hayat ile ilgili toplumsal çalışılmıştır. Huristiyan sıklıkla "Tanrı baba ve

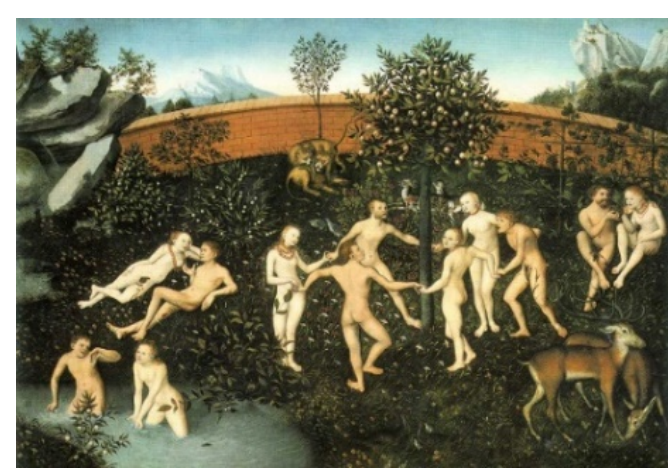
yaşayacaklarına 19-21). Eski ve Yeni Yeryüzü Cenneti ve 10) uzun y1llar ikonografik söylem önemli bir yer söylem olarak alanda ölüm sonras1 bilinç oluşturulmaya ikonografisinde ilk insan çifti: Adem ile Havva, bahçe resimlerinde sürekli yeniden ortaya çıkar. Hz. İsa da bazen -Yuhanna 20,17'ye gönderme yapılarak- bahçıvan olarak betimlenir (Mayer-Tasch, 2003, 17)". İnançlıların ölüm sonrası sonsuz mutluluğa ulaşmaları için tıpkı peygamberleri gibi çilekeş bir hayatı sürerek ancak

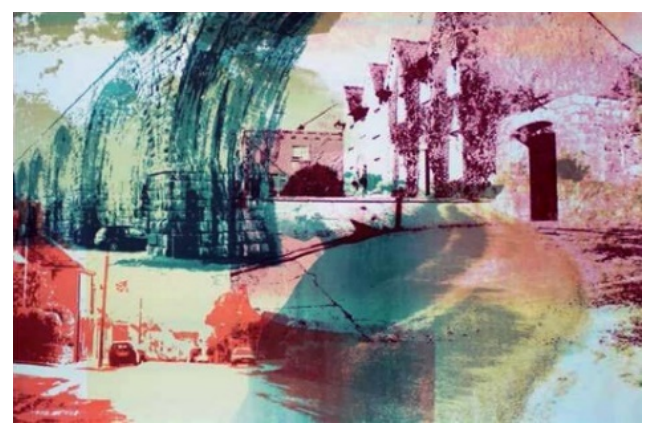
ona kavuşabilirlerdi.

Görüntü 6. Lucas Cranach the Elder, “Altın Çağ”, 73 x 105 cm, Ahşap Panel üzerine yağlıboya, 1530, Alte Pinakothek, Munih. Kaynak: http://www.abbeville.com 
Görüntü 7. Emma Finucane, "Panchaea: Güvensizlik Duygusunun Azaltıması ve Eşit Utopya üzerine bir araştırma projesi için çalışma: Mick İçin”, 60 x 41,5 cm, Kâğıt üzerine Serigrafi, 2013, Görsel Sanatlar Galerisi, Carlow. Kaynak: http://www.judodesign.com

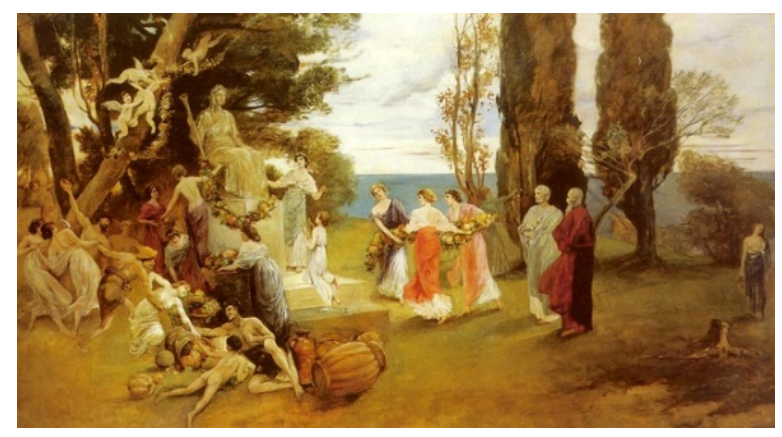

Görüntü 8. Friedrich August von Kaulbach, “Arcadia'da”, 128 x 229 cm, Tuval üzerine yağlıboya, 1880, Özel Kolleksiyon. Kaynak: http://www.artnet.com ve http://en.wikipedia.org

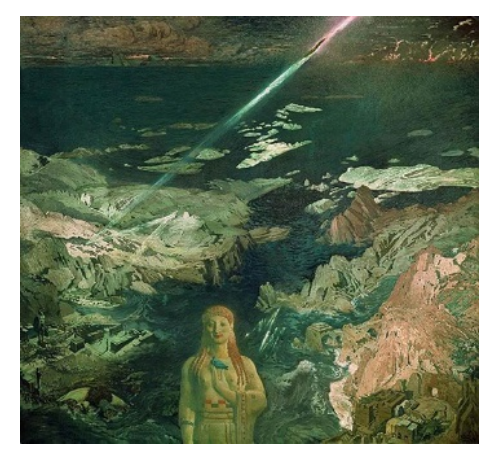

Görüntü 9. Leon Bakst, “Terror Antiquus- Atlantis’in Yıkımı”, 250 x $270 \mathrm{~cm}$, Tuval üzerine yağlıboya, 1908, Rusya Devlet Müzesi, St. Petersburg. Kaynak: Gibson, 1995, 180.

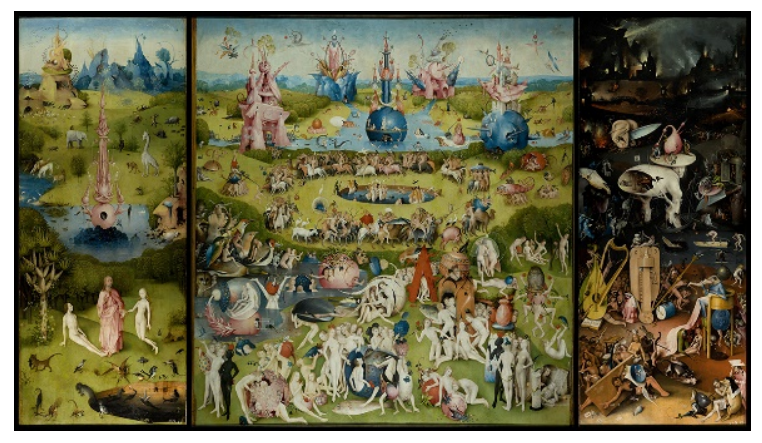

Görüntü 10. Hieronymus Bosch, "Dünyevi Hazlar Bahçesi”, 220 x389 cm, Ahşap panel üzerine yağlıboya, 1503-1504, Prado Müzesi, Madrid. Kaynak: http://tr.wikipedia.org

Uzun yıllar boyunca Hıristiyanlık inancının ve kilisenin baskılayıcı uygulamalarına karşın Antik Greko-Romen ve diğer Avrupa pagan kültürlerin mirası olan ütopik mitsel söylemler yok olmamış, 14. yüzyıldan itibaren seküler söylemlere dönüşerek yeniden gün yüzüne çıkmıştır. Yaklaşık 1330'lu yıllarda ozanlar tarafından dillendirilen The Land of Cockaigne-Gençlik Ülkesi (Görüntü 11-12) bu bağlamda değerlendirilebilir. Cockaigne, kilisenin anlattığı ölüm sonrası cennetten çok daha çekici ve güzeldir. Eski ve Yeni Ahit’te anlatılan cennet tasvirinin: yeşil bahçeler içinde ırmakların aktığı, binbir türlü çiçek ve meyvelerin ağaç dallarından sarktığı, çeşit çeşit yabani hayvanların sükûnet içinde yaşadığ yabanıl doğanın tam tersine; Gençlik Ülkesi'nde ırmaklardan yağ, bal, süt ve meyler akar, 
hertürlü yiyeceklerin en iyisi bulunur, emek sarfedilmeden pişirilmiş ve hazırlanmış türlü türlü yiyecekler bulunur; insanlar yattıkları yerden zahmetsizce bu nimetlerin keyfini yaşarlar (Göktürk, 1982, 24).

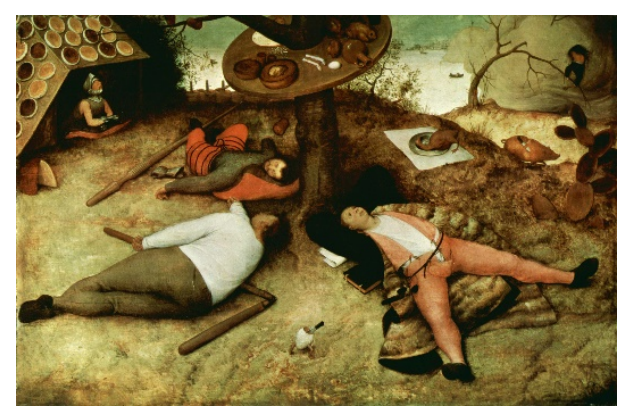

Görüntü 11. Pieter Brueghel the Elder, "The Land of Cockaigne, Gençlik Ülkesi”, 52 x $78 \mathrm{~cm}$, Ahşap panel üzerine yağlıboya, 1567, Alte Pinakothek, Munih. Kaynak: http://en.wikipedia.org

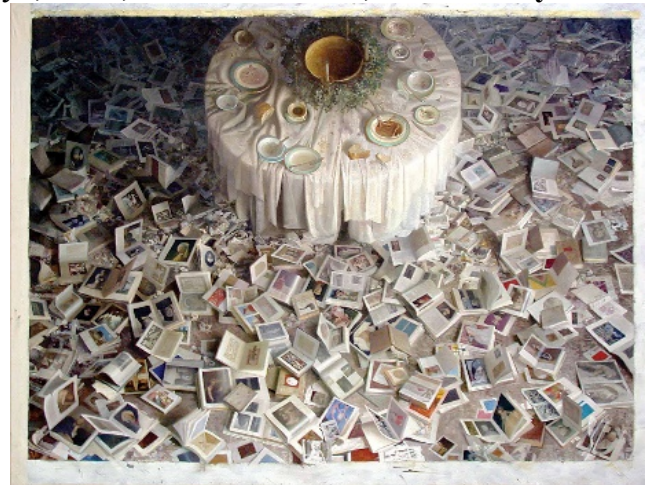

Görüntü 12. Vincent Desiderio “Cockaigne, Gençlik Ülkesi”, 284,8 x 389,6 cm, Tuval üzerine yağlıboya, 1993-2003, Hirshorn Müzesi ve Heykel Galerisi, Washington.

Kaynak: http://hirshhorn.si.edu/

Esasında Hıristiyanlık inancına karşıt ütopik söylem ve cennet miti o dönem Avrupa'da var olan kilisenin baskıcı yaklaşımının ve fakirliğin gittikçe yaygınlaşmasının sonucudur. Yeni keşifler ve Aydınlanma öncesi döneme kadar Doğu toplumlarının refah düzeyi Batı toplumlarına göre daha üst seviyedeydi. Ortaçağ boyunca siyasi ve iktisadi darboğaz Avrupa'daki halk kitleleri üzerinde toplumsal her alanında derin izler bırakmıştı. İnsanlık tarihinin antik dönem söylencelerinden keşifler döneminin başlangıcı sayılabilecek Yeniçağ'a kadar var olan dünya algısını ve buna dair söylemlerin değişimini; suların sonsuzluğu, kaos kuşağı ve bilinmezlikle çevrili bir üç kıtanın tamamını (Asya, Afrika, Avrupa) kapsayan oikumene kavramını büyük keşif yolculukları çözmüş̧; tek gözlü ejderlerle ve tuhaf halklarla ilgili akıl almaz masallar silinmeye başlamıştır. Sırrına erişilmemiş dördüncü kıta başka söylenceleri ortaya çıkarmıştır Denizciler keşfedilmiş bu yeryüzü cennetinin "Yeni Dünya-Amerika" ve ilkel iyi insanın temsilinin soyağacının köklerini yaratmışlardır (Mattelart, 2005, 23). Bu Yeni Dünya söylemi, tıpkı The Land of CockaigneGençlik Ülkesi söylemindeki karşıt cennet ve ütopya kurgusu gibi, eski olanın ve tüm çaresizliği ile içinde yaşanılan toplumun yozlaşmış durumuna karşı bir kurtuluş veya kaçış olarak alternatif bir yer olmuştur. Antik dönemden bugüne tüm ütopyacı söylemler var oldukları dönemlerinin koşullarının sonucuna uygun biçimde oluşturulmuşlardır (Notos,2012, 52). "Ancak ütopya kurgusu, çoğu zaman her biri dönemin ekonomik, sosyal, siyasal, askeri ve hatta psikolojik olumsuzluklarına atfedilerek üretilmiş ve dönemlerine ait memnuniyetsizliklerin birer yansıması olarak ortaya konmuştur (Bayartan, 2009, 70)”.

Siyasal ve sosyal sıkıntıların yaşandığı dönemlerde, ütopyacı düşüncelerin yaygınlaştığı görülür. Özellikle Platon'un Devlet'inde vurgulanan ideal toplum düzeniyle 
ilgili düşünceler, sonraki dönemlerdeki ütopyacı söylemlere temel kaynak oluşturmuş, bu söylemlerin kavramsal ve terimsel çerçevesi Thomas More'un Utopia'sında kesinliğe kavuşmuştur. 1516 yılında, Thomas More Latince olarak yazdığ ve İngilizce basımı 1551 yılında yapılmış olan Yeni Siyasi Topluluk Biçimi ve Yeni Ütopya Adası, yani Utopia (Görüntü 13-14) iki bölüm olarak ve ilkin ikinci bölümü yayınlanmıştır. İkinci bölümde İtalyan denizci ve kâş̧if Amerigo Vespucci'nin mürettebatlarından biri olduğu varsayılan hayali bir karakter olması muhtemel- Portekizli filozof ve denizci Raphael Hytholday'in anı ve sözlerinden anlatılan, Kral Utopus'un yönettiği mutlak eşitlik ülkesi Utopia'lıların adası tasvir edilir. Thomas More'un daha sonra yazdığı birinci bölümde, ikinci bölüme göre tersi bir kurgu içinde dünya betimlenmiştir. Yazarın kendi yaşadığı dönemin İngiltere'sindeki siyasal ve toplumsal durumu içerdiği için gizli bir siyasi eleştiri barındırır. (MadonnaDesbazille, 2003, 256-260; Mattelart, 2005, 29; Urgan, 2000, 47). Böylelikle More, kitabında bahsettiği Utopia'lıların adasındaki siyasal eşitlikçi mutluluk adası örneğinden yola çıkarak, kendi yaşadığı toplumun ve siyasal yaşantının yozluğunun nasıl düzeltilebileceğini göstermek ister. Fransız ve Sanayi Devrimleri sonucunda Avrupa'da siyasal ve toplumsal yapılarda köktenci değişimler olmuş; bu atmosfer ortamında sanatçılar siyasiler ve düşünürler tarafından, özellikle 19. yüzyıldan itibaren ütopik söylemler: Palton'un Devlet ve Thomas More'un Utopia'sına atfedilerek siyasi ve toplumsal anlamlar bağlamında değerlendirilmeye çalışılmıştır. 20. yüzyılda ütopik söylem avangart sanatçılar tarafindan sanatsal pratiklerinin nihai amacı olarak vurgulanmış; ayrıca, bu ülküsel yaklaşımlar etrafinda toplumsal ve siyasi söylemler üretilmiştir.

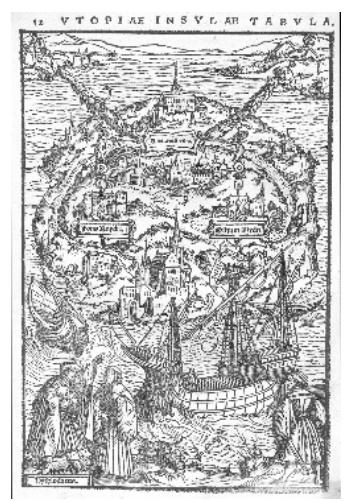

Görüntü 13. Ambrosius Holbein, "Utopiae Insulae Tabula- Ütopya Haritası”, 17,9 x 11,9 cm, Ahşap Gravür Bask1, 1518, Nadir Kitap ve Belgeler Bölümü, Princtone Üniversitesi Kütüphanesi.

Kaynak: http://libweb5.princeton.edu

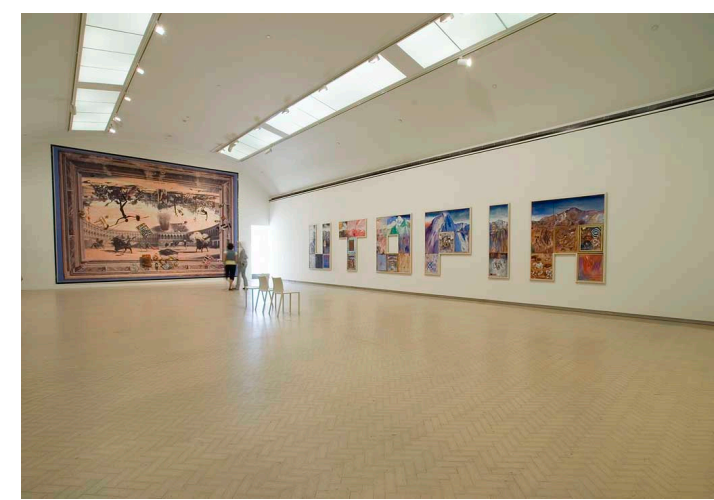

Görüntü 14. Juan Davila, “Utopia”, Sergi Alanından Yerleştirme Görünümü, Muhtelif Ebatlarda Tuval Üzerine Yağlıboya, 1998, Avusturalya Çağdaş Sanatlar Müzesi, Sidney.

Kaynak: http://www.mca.com.au/ 


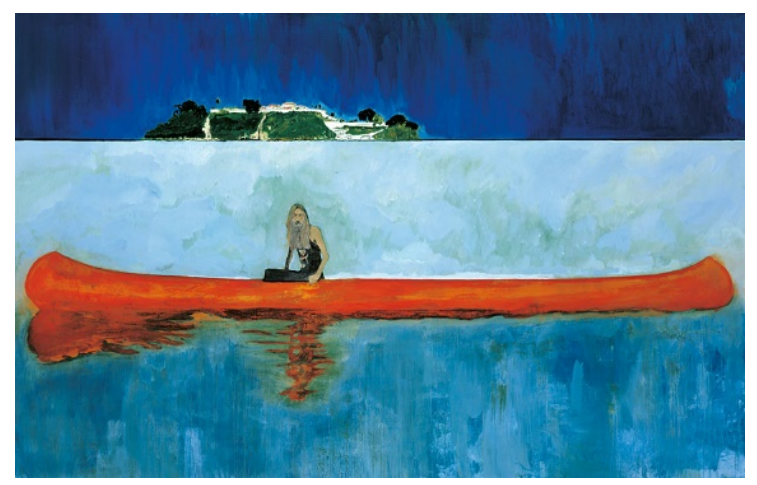

Görüntü 15. Peter Doig, “100 Y1l Önce”, 229 x 359 cm, Tuval Üzerine Yağlıboya, 2001, Centre Pompidou Ulusal Modern Sanat Müzesi, Paris. Kaynak: http://peterdoig.mbam.qc.ca/

Zaman olgusunun ve tarihsel sürecin etkisiyle birlikte; uzam da maddenin yapısındaki bulunan özelliklerden dolayı sürekli değişme sürecine maruz kalan kavramlardır. Ütopik yazın ve görsel sanatlarda yazarın, sanatçının tanımlamaya çalıştığı toplum ise en iyi, eksiksiz yaşama düzeniyle, değişime, her türlü dış etkiye kapalı kesinlikte bir örnek toplum, modeldir. Bundan dolayı, ada metaforu ütopyacı anlatılar için mükemmel bir mekân biçimidir. $\mathrm{Bu}$ bağlamda, dışarıya kapalı ada (Görüntü 15 ve 16) olgusu Platon'dan beri toplumsal ütopyalar için en uygun mekân olarak düşünülmüştür (Göktürk, 1982, 17). Bu olgunun genel adlandırılmış biçimi olarak Utopia / Eutopia adası hiçbir yerin ve mutluluğun ülkesidir. Ütopik söylemler aynı zamanda bir $U$-chronie bir süreçle tarihi durdurur ve zamansızlık ruhu taşır. $\mathrm{Bu}$ bağlamda düşsel olan bu hiçbir yer ve güzel yer Yeni Dünya ile Eski Zamanları birleştiren metaforik mekânlardır (Mattelart, 2005, 29).

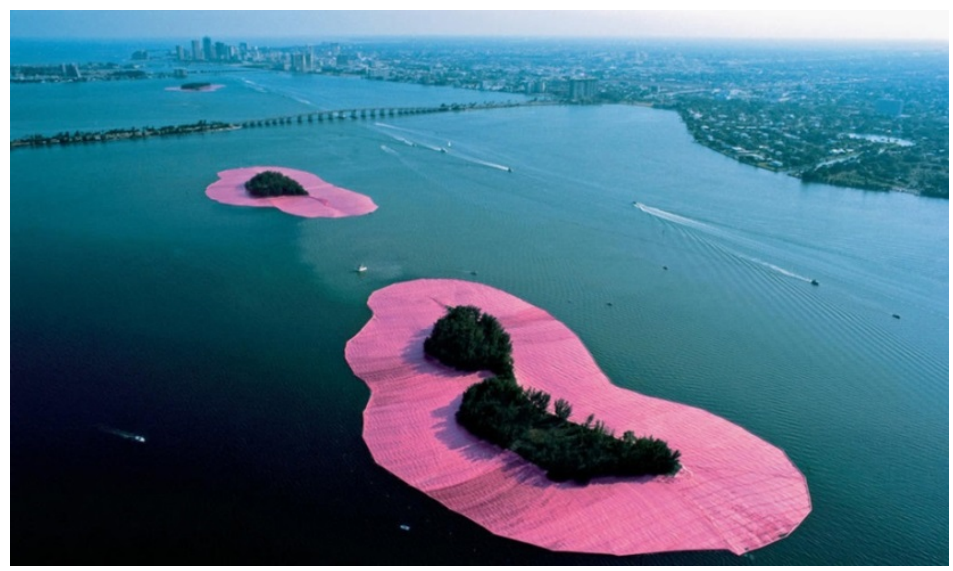

Görüntü 16. Christo ve Jeanne-Claude, Çevrelenmiş Adalar, Çevresel Sanat Projesi Biscayne Koyu, Greater Miami Florida, 1980-1983. Kaynak: www.khanacademy.org

Aynı zamanda, Ütopya olgusunun geçmiş ve gelecek zamanla ilgili var olmuşluğu veya var olabileceği ülküsü paradoks bir kavramdır. Henri Meschonnic'in belirttiği gibi, "ütopya bir paradokstur. Onun birçok anlamı vardır. Bir yer yokluğu, yerin ve zamanın dışındaki sığınak olabilir; bu ikisini ayırmak mümkün değildir. Ama ütopya, yer ve zaman üzerine fetihçi bir girişim de olabilir (Rior-Sarcey, 2002, 8)”. Her ne kadar düşünürler, yazarlar ve sanatçılar tarafından tasarlanan ütopik söylemlerin mekânsal kurguları gerçeklikle iç içe geçmiş olsa bile, sonuçta ülküsel bir düşünce olarak hayali olan biçimlerdir. Sonuç olarak, Fredric Jameson'ının da söylediği gibi; “ütopyacı düşünce [...] içinde bulunduğumuz dünyadan niteliksel olarak farklı bir dünya olasılığını canlı tutar ve mevcut olanın inatla yadsınması biçimini alır (Booker, 2012, 36)". 


\section{KAYNAKÇA}

Albig, J-U. (2009). Edebi bir arayışın öyküsü (Çev: T. Günseren, Y. Kasap, A. Sabuncuoğlu ve diğerleri). Geo G+J Magazines Dergisi, 12, 70-93

Bayartan, M. (2009). Ütopyalarda coğrafi mekân. Sosyoloji Dergisi, 18, 69-95. http://www.journals.istanbul.edu.tr/iusosyoloji/article/view/1019013235 (Erişim Tarihi: 15.05 .2015$)$

Booker, M. K. (2012). Ütopya, distopya, toplumsal eleştiri (Çev: O. Tecimen). Notos Öykü Edebiyat Dergisi, 36, 35-46

Chevalier, J.,Gheerbrant, A. (1996). Symbols. London: Penguin Books.

Doueihi, M. (2011). Yeryüzü cenneti (Çev: A. Kahiloğulları). Ankara: Dost Kitabevi.

Göktürk, A. (1982). Ada. İstanbul: Adam Yayıncılık.

Madonna-Desbazille, M. (2002). Ütopya. Ütopyalar Sözlüğ̈̈ (Ed: M. Rior-Sarcey, T. Bouchet, A. Picon). (Çev: T. Ilgaz). İstanbul: Sel Yayıncılık.

Mattelart, A. (2005). Gezegensel ütopya. (Çev: Ş.Çiltaş). İstanbul: Ayrıntı Yayınları.

Mayer-Tasch, P. C. (2003). Cennet bahçesi. Bahçelerin ve Parkların Tarihi. (Ed: H. Sarkowicz). (Çev: E. Kayaoğlu). Ankara: Dost Kitabevi.

Nişanyan, S. (2009). Sözlerin soyağacı. (4. Bask1). İstanbul: Everest Yayınları.

Notos Öykü (2012). Ütopya Edebiyatı Kitaplarl Aylık Edebiyat Dergisi, 36, İstanbul: Notos Kitap Yayınevi.

Rior-Sarcey, M. (2002). Giriş. Ütopyalar Sözlüğ̈̈. (Ed: M. Rior-Sarcey, T. Bouchet, A. Picon). (Çev: T. Ilgaz). İstanbul: Sel Yayıncılık.

Urgan, M. (2000). Thomas More, Utopia (Çev: V. Günyol, S. Eyüboğlu, M.Urgan). İstanbul: Türkiye İş Bankası Kültür Yayınları.

http://www.etymonline.com/index.php?allowed_in_frame $=0 \&$ search $=$ garden $\% 2 \mathrm{C}+$ paradise $\%$ $2 \mathrm{C}+$ heaven $\% 2 \mathrm{C}+$ himmel\%2C + ciel\&searchmode=none ( Erişim Tarihi: 03.02.2015)

\section{GÖRÜNTÜ VE TABLO KAYNAKÇASI}

Görüntü 1. R. H. Quaytman, “Sürgün, Bölümler 20”,82,2 x $133 \mathrm{~cm}$, Ahşap üzerine yağlıboya, serigrafi ve gesso, 2010, Miguel Abreu Galerisi, New York.

Kaynak:http://www.miguelabreugallery.com/R.H.Quaytman/2010_chpt20/works/4.htm (Erişim Tarihi: 25.05.2015) ve Schwabsky, B. (2011). Vitamin P2, New Perspectives in Painting. New York: Phaidon Press Inc.

Görüntü 2. Jan Brueghel the Elder ve Peter Paul Rubens, "İnsanın Düşüşü, Adem ile Havva Den Bahçesinde",74,3x114,7 cm, Tuval üzerine yağlıboya, 1615, Maurithuis Kraliyet Resim Galerisi Lahey. Kaynak: https://www.mauritshuis.n1/en/explore/thecollection/artworks/the-garden-of-eden-with-the-fall-of-man-253/ (Erişim Tarihi: 20.03.2015).

Görüntü 3. Detay, "Bahar Manzarası", Minos Uygarlığı Akrotiri bölgesinden rekonstrüksiyon Fresk, M.Ö. 1630-1500, Cyclades, Thera. Kaynak: Stokstad, M. (1999). Art History. Cilt (1). Newyork: Harry N. Abrams Inc. Publishers,.

Görüntü 4. Detay, “Bahçe Görünümü”, Livia Villası'nda İkinci Stil Fresk, M.Ö. 1. Yüzyıl, Prima Porta, Roma. Kaynak: Stokstad, M. (1999), Art History, Cilt (1), Newyork : Harry N. Abrams Inc. Publishers.

Görüntü 5. "Babür Şah Bahçe Çalışmalarını Denetliyor", 16. Yüzyıl Hint Minyatürü. Kaynak: Sarkowicz, H. (2003). Bahçelerin ve Parkların Tarihi. (Çev. E. Kayaoğlu). Ankara: Dost Kitabevi.

Görüntü 6. Lucas Cranach the Elder, "Altın Çağ", 73 x 105 cm, Ahşap Panel üzerine yağlıboya, 1530, Alte Pinakothek, Münih. Kaynak: http://www.abbeville.com/interiors.asp?ISBN=9780789209931\&CaptionNumber=02 (Erişim Tarihi: 10.04.2015).

Görüntü 7. Emma Finucane, "Panchaea: Eşit Utopya ve Güvensizlik Duygusunun Azaltıması üzerine bir araştırma projesi için çalışma: Mick İçin”, 60 x 41,5 cm, Kâğı̈t üzerine Serigrafi, 2013, Görsel Sanatlar Galerisi, Carlow. Kaynak: 
http://www.judodesign.com/wp-content/uploads/2015/04/Panchaea_web.pdf (Erişim Tarihi: 13.03.2015).

Görüntü 8. Friedrich August von Kaulbach, “Arcadia'da”, 128 x 229 cm, Tuval üzerine yağlıboya, 1880, Özel Kolleksiyon. Kaynak:http://www.artnet.com/artists/friedrichaugust-von-kaulbach/in-arcadia-7jXXzI-SZ0URFnCHBo_LNg2 (Erişim Tarihi: 13.03.2015).

http://en.wikipedia.org/wiki/Arcadia_(utopia)\#/media/File:Friedrich_August_von_Ka ulbach___In_Arcadia.jpg (Erişim Tarihi: 13.03.2015).

Görüntü 9. Leon Bakst, “Terror Antiquus- Atlantis'in Y1kımı”, 250 x $270 \mathrm{~cm}$, Tuval üzerine yağlıboya, 1908, Rusya Devlet Müzesi, St. Petersburg. Kaynak: Gibson, M. (1995). Symbolism. Köln: Benedict Taschen.

Görüntü 10. Hieronymus Bosch, "Dünyevi Hazlar Bahçesi”, 220 x389 cm, Ahşap panel üzerine yağlıboya, 1503-1504, Prado Müzesi, Madrid. Kaynak: http://tr.wikipedia.org/ wiki/Dünyevi_Zevkler_Bahçesi (Erişim Tarihi: 09.02.2015).

Görüntü 11. Pieter Brueghel the Elder, "Gençlik Ülkesi”, 52 x $78 \mathrm{~cm}$, Ahşap panel üzerine yağlıboya, 1567, Alte Pinakothek, Munih. Kaynak: http://en.wikipedia.org/ Cockaigne\#/media/File:Pieter_Bruegel_d._\%C3\%84._037.jpg (Erişim Tarihi: 09.02.2015).

Görüntü 12. Vincent Desiderio “ Cockaigne, Gençlik Ülkesi”, 284,8 x 389,6 cm, Tuval üzerine yağlıboya, 1993-2003, Hirshorn Müzesi ve Heykel Galerisi, Washington.Kaynak:http://hirshhorn.si.edu/search-results/

?edan_search_value $=$ Vincent $\% 20$ Desiderio\#detail=http $\% 3 \mathrm{~A} / / \mathrm{hirsh}$ orn.si.edu/search -results/search-result-details/\%3Fedan_search_value\%3Dhmsg_04.19 (Erişim Tarihi: 24.05.2015).

Görüntü 13. Ambrosius Holbein, "Utopiae Insulae Tabula- Ütopya Haritası", 17,9 x 11,9 cm, Ahşap Gravür Baskı, 1518, Nadir Kitap ve Belgeler Bölümü, Princeton Üniversitesi Kütüphanesi.

Kaynak:http://libweb5.princeton.edu/visual_materials/maps/websites/thematicmaps/theme-maps/utopia.html (Erişim Tarihi: 13.04.2015).

Görüntü 14. Juan Davila, "Utopia", Sergi alanından yerleştirme görünümü, Mühtelif ebatlarda Tuval üzerine yağlıboya, 1998, Avusturalya Çağdaş Sanatlar Müzesi, Sidney. Kaynak: http://www.mca.com.au/collection/exhibition/390-juan-davila/ (Erişim Tarihi: 20.05.2015).

Görüntü 15. Peter Doig, “100 yıl önce”, 229 x 359 cm, Tuval üzerine yağlıboya, 2001, Centre Pompidou Ulusal Modern Sanat Müzesi, Paris. Kaynak: http://peterdoig.mbam.qc.ca/en/gallery/ (Erişim Tarihi: 20.05.2015).

Görüntü 16. Christo ve Jeanne-Claude, Çevrelenmiş Adalar, Çevresel Sanat Projesi Biscayne Koyu, Greater Miami Florida, 1980-1983. Kaynak: https://www.khanacademy.org/humanities/art-1010/minimalism-earthworks/a/christoand-jeanne-claude-the-gates (Erişim Tarihi: 20.08.2015). 